\title{
Statistical analysis of the processes of intensification of the introduction of information and communication technologies in the socio- economic sphere of the Russian Federation
}

\author{
Irina A. Kislaya, Galina A. Bondarenko, Anna A. Rudyaga, and Sergey S. Aslanyan \\ Rostov State University of Economics, Bolshaya Sadovaya St. 69, 344002 Rostov-on-Don, Russia
}

\begin{abstract}
The article analyzes the effectiveness of the development of digitalization processes in the socio-economic sphere of the Russian Federation and its territorial entities. Based on the information arrays of the Federal statistical observation on the use of information technologies and information and telecommunications networks by the population, the level of use of information and communication technologies by the population of the Russian Federation in everyday life is studied. In order to deepen the analysis, the authors produced a ranking of regions of southern Federal district by key indicators, characterizing the use information and communication technologies in 2019 by its population, allowing to allocate and justify the leading factors in the development of the information society and the intensification of the processes of digitalization of economy and social sphere of regions. The authors formulated a number of recommendations for the further development of the information society in the Russian Federation and its territorial entities.
\end{abstract}

\section{Introduction}

One of the most important tasks of implementing the process of digitalization of the economy is to improve the quality of life of the population by opening new directions for development and increasing human capital, expanding the accessible environment for people with disabilities. In turn, the digital economy also imposes new requirements for the individual: the ability to work with information and communication technologies (ICT) and to apply innovative products for professional and personal needs. In this regard, there is a pressing need for statistical analysis and assessment of the readiness of the population to move to a qualitatively new level of social development.

In terms of the high degree of territorial differentiation in the Russian Federation, it is very difficult to assess the readiness of the transition to the digital economy at the regional level. This is due to the fact that many of the indicators that characterize the process of digitalization of the economy and are calculated at the country level as a whole are not used in the formation of regional information resources.

Along with the above, today, the solution of the problem of obtaining an assessment of the compliance of regional development with the challenges of the digital economy is 
relevant and significant. First, diversification of the processes of regional informatization unable to restrain the total transition to the digital economy of the country, and second, the developed methodology for assessment of compliance of the regions to the challenges of the digital economy is necessary for maximizing the economic benefits from the use of this type of information technology.

\section{Materials and methods}

In this study, information resources of the Federal state statistics service ("Rosstat") were used, in particular, data from the sample Federal statistical observation on the use of information technologies and information and telecommunications networks by the population (hereinafter referred to as the "ICT survey") [1].

The most important area of application of the information arrays of the abovementioned survey is the analysis of the results of implementation of major state programmes aimed at the development of the information society and the digital economy, monitoring the implementation of Goals of sustainable development and the realization of inter-territorial comparisons, including ratings of the level of ICT development.

In this study, the authors used data from a sample survey of ICT to rank the regions of the southern Federal district based on non-parametric methods of analysis and evaluation, in particular, on the basis of the Pattern method. This method is based on the estimation of a multidimensional average value based on the formula of the arithmetic mean simple, calculated from the relative values of comparison of territorial entities by the best value of the indicator for each component of the information system under study [2].

Thus, the Pattern method allows to bring various indicators to a single comparison base, calculate the integral indicator of the studied area and on this basis make a rating assessment of territories, which will allow to identify areas of sustainable growth or insufficient development of the phenomenon under study, which is the basis for developing recommendations for improving the situation within a specific territorial entity.

\section{Results and Discussion}

In order to conduct statistical analysis and evaluation of the processes of digitalization of economy and social sphere, as well as the intensification of ICT use in the everyday life of the population of the Russian Federation and southern Federal district (SFD), the authors developed an algorithm comprising the following steps:

- selecting of indicators from the information base of the ICT surveys in 2019 as characteristics of information society development in Russia;

- conducting a comparative assessment of the selected indicators for the Russian Federation and the southern Federal district;

- implementation of the rating assessment of the entities of the southern Federal district based on the main criteria that characterize the intensity of the population's use of the Internet in their daily lives;

- evaluation of use of state and municipal services by the population of the southern Federal district via the Internet, as the most important factor in the intensification of the introduction of ICT in the socio-economic sphere of territorial entities;

- identifying points of growth and slowing down the intensification of digitalization processes in the regions of the southern Federal district.

According to the authors, the use of this algorithm will enable the analysis and make a conclusion about the nature and intensity of development of information society and the speed of introduction of ICT in socio-economic sphere of the territorial entities of the 
Southern Federal district, that will expand the information base of regional statistics in this area and will enable governments to make effective decisions in terms of achieving the goals of sustainable development.

Based on the data from the ICT survey for 2019, authors selected the main indicators that characterize the degree of use of the Internet by the population of the Russian Federation and the southern Federal district (see figure 1).

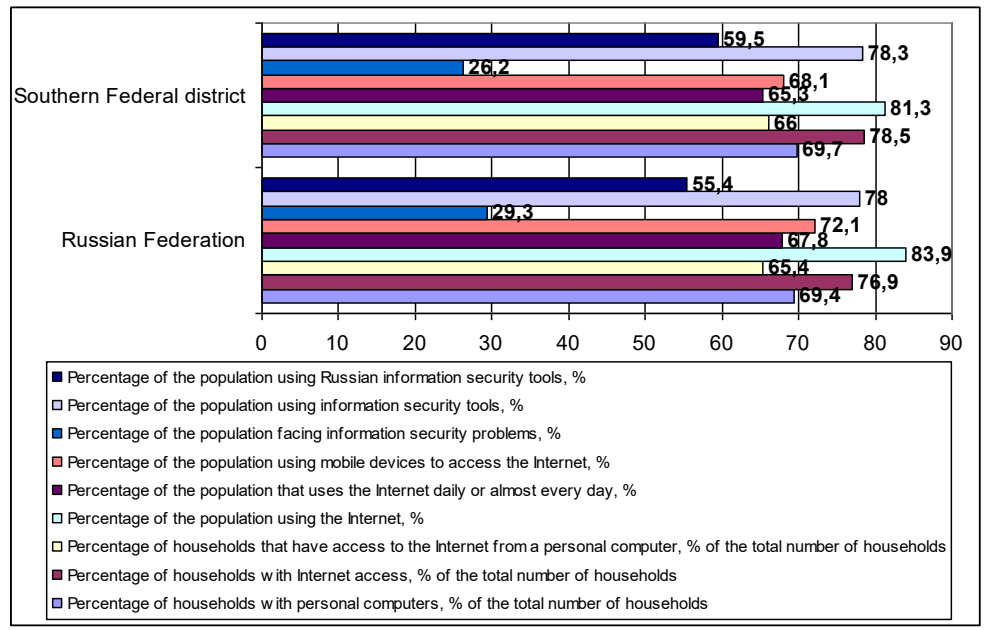

Fig. 1. Key indicators that characterize the use of the Internet by the population of the Russian Federation and the Southern Federal district in 2019 [1]

Figure 1 shows that the population of the Russian Federation and the Southern Federal district actively uses mobile devices to access the Internet. At the same time, more than two-thirds of the population of the studied territories use information security tools, while about a quarter of the population faced it security problems in 2019. Thus, we can conclude that digitalization processes are actively being implemented in the daily life of the population of Russian Federation.

According to figure 2, people aged 25-39 years, either in Russia or in the Southern Federal district, were the most active users the Internet in their work and daily life in 2019. We should also notice a rather high level of Internet users in the age group of 60-69 years, which indicates the involvement of citizens of pre-retirement and retirement age in the processes of digitalization of the socio-economic sphere of the country and its regions.

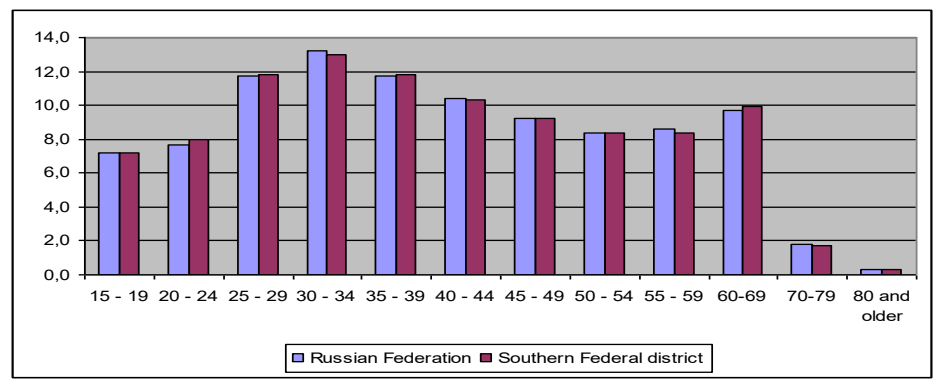

Fig. 2. Age structure of the population of the Russian Federation and the southern Federal district aged 15 years and older who actively use the Internet [1]

According to the ICT survey, in 2019, in most cases, the population of the Russian Federation and the Southern Federal district aged 15 years and older used the Internet at 
home $(96.1 \%$ and $97.4 \%$ of the total population of the surveyed age who used the Internet, respectively), at work ( $46.1 \%$ and $42.3 \%$, respectively), in public access points (hotels, airports, cafes, etc.) (31.5\% and $26.3 \%$, respectively).

According to the results of the ICT survey, the majority of the population of the Russian Federation and the southern Federal district in 2019 preferred to use a smartphone to access the Internet via a cellular telephone network $(65.5 \%$ and $60.5 \%$, respectively) and via wireless networks ( $40.1 \%$ and $35.5 \%$, respectively). Other types of mobile devices (laptops and tablets) were used by $5-8 \%$ of the population of the Russian Federation and the Southern Federal district.

According to the ICT survey, the largest part of the population of the Russian Federation and the southern Federal district in 2019 faced such problems as unauthorized mailing $(22.2 \%$ and $21.6 \%$, respectively) and infection of devices with virus components (7.5\% and $6.5 \%$, respectively).

Thus in 2019, population's of Russia and Southern Federal district the most common means of information protection were antivirus programs (75,5 \% and $76.4 \%$, respectively) and anti-spam filters (18.4\% and $20.7 \%$ respectively).

The results of the ICT survey allowed authors to identify the most common reasons for the refusal to use the Internet by the population of the Russian Federation and the Southern Federal district in 2019. These include: lack of need or desire $(75.4 \%$ and $74.9 \%$, respectively), insufficient level of Internet skills $(34.1 \%$ and $36.0 \%$, respectively), sufficiently high cost of connecting to the Internet (13.2\% and $13.1 \%$, respectively), the presence of certain technical difficulties associated with connecting to the Internet $(4.1 \%$ and $4.7 \%$, respectively), ensuring the security of personal data $(3.0 \%$ and $3.1 \%$, respectively) [1].

The next stage of the authors' algorithm for studying the processes of digitalization of the socio-economic sphere of the Russian Federation and its territorial entities is ranking of the Southern Federal district regions by the main indicators of ICT use by the population in 2019 based on the Pattern method, which includes the following set of criteria:

- the percentage of households connected to the Internet from a personal computer [1];

- the percentage of the population that uses the Internet at work and in everyday life [1];

- $\quad$ the percentage of the population using mobile devices to connect the Internet [1];

- the percentage of the population facing it security problems [1];

- the percentage of the population using various information security tools [1];

- the percentage of the population that ordered goods and/or services via the Internet [1];

- the percentage of the population that interacted with state and local authorities via the Internet [1];

- the percentage of the population who used mobile devices in obtaining state and municipal services through official websites and portals [1];

- the percentage of the population who faced problems in obtaining state and municipal services through official websites and portals [1];

- the percentage of the population who fully satisfied with the quality of state and municipal services provided in electronic form [1].

The results of ranking the regions of the Southern Federal district based on the multidimensional average of the indicators calculated using the Pattern method for 2019 are shown in figure 3.

Based on the data in figure 3, it is clear that the Republic of Adygea is the leader among the regions of the Southern Federal district in terms of ICT use, mainly due to a significant proportion of the population using mobile devices connected to the Internet, and a high 
overall degree of satisfaction with the quality of state and municipal services provided in electronic form due to the minimum number of problems in obtaining this type of services through electronic portals. Also, we should note the small proportion of the population of the Republic of Adygea, faced with information security problems.

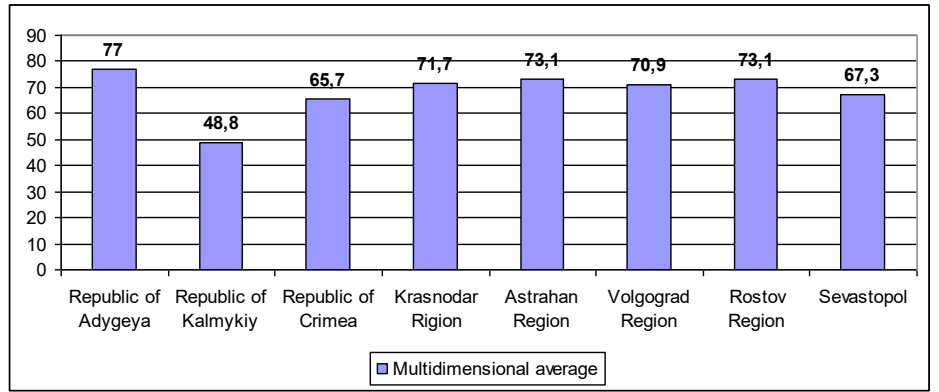

Fig. 3. Ranking of subjects of the southern Federal district by the generalizing criterion of the level of ICT use by the population in 2019

The group of regions that have a fairly high level of ICT use by the population includes the Astrakhan, Rostov, Volgograd and the Krasnodar regions. These territories are generally characterized by a high proportion of the population using the Internet, including for state and municipal services and using mobile devices connected to the Internet, as well as using information security tools.

The regions with an average level of ICT use by the population are Sevastopol and the Republic of Crimea. In these subjects, the proportion of the population using the Internet, including from a personal computer, is quite high. In the Republic of Crimea in 2019, the largest share of the population who used information security tools was recorded, and in Sevastopol - the population who ordered goods or services via the Internet.

The Republic of Kalmykia is in the last place in this rating, due to the fact that in 2019 there was a fairly high proportion of the population that faced problems with it security and receiving state and municipal services via the Internet, as well as a low proportion of the population that ordered goods and services via the Internet.

In General, the so-called Electronic government services (E-government services) are developing quite actively, allowing the population to get a huge range of state and municipal services without leaving home via the Internet. So, in 2019, the most popular EGovernment services received by the population of the Southern Federal district via the Internet were the following: making an appointment and receiving other services by healthcare organizations (52.4\%), making tax payments and fees (37.4\%), services provided by the Ministry of internal Affairs and the State road safety Inspectorate $(28.4 \%)$, services of housing and communal services (19.7\%), services of educational organizations (12.6\%), services for obtaining a passport/registration (11.9\%), services of organizations, providing social security for the population $(8.9 \%)$. [1].

In most cases, the population of the Southern Federal district applied to E-Government services to obtain the necessary data through official websites and portals of state and municipal services $(72.8 \%)$, make an appointment $(59.8 \%)$, make mandatory payments and fees $(48.3 \%)$, download standard forms of necessary documents $(40.6 \%)$, send electronic forms of documents $(37.1 \%)$, and receive results of providing E-Government services $(36.2 \%)[1]$.

At the same time, most of the problems faced by the population of the Southern Federal district regions in the process of obtaining E-Government services via the Internet in 2019 were related to technical problems $(16.3 \%)$. And only $5.8 \%$ of respondents noted 
difficulties in obtaining reliable information, while $2.7 \%$ of respondents could not get explanations and assistance in obtaining a particular electronic service [1].

In General, the study of ICT use by the population of the Russian Federation indicates a high degree of ICT coverage and the quality of information provided, the availability of a particular type of service on the electronic portals of state and municipal services. However, the public authorities should pay attention to improving the level of technical support for these services.

\section{Conclusions}

The study of the processes of intensification of ICT in socio-economic development of the Russian Federation and the subjects of the Southern Federal district in 2019 has allowed to draw some conclusions:

- information base of the ICT survey allows to provide statistical analysis and evaluation of the processes of the digitalization of the socio-economic sphere both in the territorial and temporal aspects;

- the study showed a high degree of use of ICT by the population of the Russian Federation as a whole and the Southern Federal district, in particular, in their daily lives;

- the most active Internet users in 2019 in the Russian Federation and the Southern Federal district were the population aged 25-39 years, however, the share of Internet users in the pre-retirement and pension age was also high. Consequently, public authorities should consider features of this age group during the implementation of the concept of digitalization of economy and social sphere, to develop assistance programs to expand the opportunities of e-services to this category of population;

- the results showed a high degree of use of mobile devices by the population, in particular mobile phones, for accessing the Internet, purchasing goods and receiving various electronic services. Therefore, in the future it is necessary to expand the network of cellular stations, thereby improving the quality and speed of the Internet, as well as to reduce the cost of using the Internet via mobile phones. An important aspect is the development and improvement of special mobile versions and applications for electronic portals that provide state and municipal services to the population;

- the study revealed a small proportion of the population faced information security problems and a fairly high degree of loyalty of the population of the Russian Federation to domestic information security protection tools, which creates prospects for the active development of the Russian market of computer and information security products, thereby minimizing the losses of possible sanctions measures from other countries aimed at this area;

- the ranking of Southern Federal district's territorial entities of the ICT use in 2019 showed that the leading factors in the development of the information society and the intensification of the processes of digitalization of the economy and the social sphere were the use state and municipal Internet portals, including via mobile devices by the population, and high degree of it information security. Therefore, it is necessary to transfer the most part of the state document flow to an electronic format, and in the future - fully provide this type of service via the Internet. Along with this, there is a need to develop mobile versions of websites of state and municipal authorities in order to facilitate access to them for all users, to fill them with high-quality content and to ensure the safety of users ' personal data. 
The authors believe that these actions will help to speed up the process of digitalization of the economy and social sphere both in the Russian Federation as a whole and in its territorial entities.

\section{References}

1. Official website of the Federal state statistics service, https://rosstat.gov.ru/

2. I. A. Polyakova, E. M. Polyakova, G. A. Bondarenko, Yu. I. Ivashchenko, Structural differences and rating of the most important areas of the region: modern methods of statistical research, 32 (2017)

3. I. A. Polyakova, G. A. Bondarenko, Accounting and statistics, 1(45), 49 (2018)

4. I. A. Polyakova, E. N. Makarenko, E. M. Polyakova, Information and analytical support for monitoring: methodological and applied aspects, 117 (2018)

5. Eliseeva I. I., Statistics in the digital economy: training and use, 16 (2018)

6. Kupriyanov S. V., Stryabkova E. A., Zarkovich A.V., Economic Sciences: fundamental research, 9, 809 (2014)

7. E.N. Makarenko, N.N. Khakhonova, T.V. Makarenko, I.A. Kislaya. Models of Modern Information Economy: Conceptual Contradictions and Practical Examples, 409 (2020)

8. I.A. Polyakova, D.A. Mikhailin, V.A. Guzey, A.A. Rudyaga, European Research Studies, 20, 202 (2019) 